\title{
EXPERIMENTAL INVESTIGATION ON THE TORSION-SHEAR BEHAVIOUR AT THE INTERFACES OF INTERLOCKING MASONRY BLOCK ASSEMBLAGES
}

\author{
CLAUDIA CASAPULLA ${ }^{1 *}$, ELHAM MOUSAVIAN ${ }^{1}$, LUCA U. ARGIENTO $^{1}$ AND \\ CARLA CERALDI ${ }^{1}$
}

\author{
${ }^{1}$ Department of Structures for Engineering and Architecture (DiSt) \\ University of Napoli Federico II \\ Via Forno vecchio, 36 - 80134 Napoli, Italy \\ e-mail: casacla@unina.it (*corresponding author) \\ email: \{elham.mousavian, lucaumberto.argiento, ceraldi\}@unina.it
}

Keywords: Masonry, Interlocking Blocks, Initial Shear Strength, Torsion-Shear Resistance

\begin{abstract}
This paper presents an experimental investigation on the initial shear (cohesion) and torsion-shear strengths at the interface of an interlocking masonry block. An interlocking block is a rigid unit with locks avoiding the block to slide. This improves the seismic response of dry jointed assemblages of masonry structures subjected to in-plane and out-of-plane loading. The experimental investigation is designed and carried out for the corrugated interface having one lock with rectangular cross section, i.e. the specimen is an interlocking unit composed of a main body and a lock located on the upper face of the main body. Cementbased mortars are selected to reproduce the specimen, casted using a mould provided by a $3 D$ printer, and both the lock and the main body are kept rigid during the tests. The initial shear and torsion-shear capacities of the interface at which the lock is connected to the main body are assessed together with its quasi-brittle fracture and registered in terms of loaddisplacement curves. In the designed setup, the horizontal force is applied to the rigid lock until it is disjointed from the rigid main body of the block, while the effect of rocking during the shear test is avoided. The force and the displacements are measured using a load cell and Linear Variable Displacement Transducers (LVDTs), respectively. The experimental programme includes four different sets with different load application points and different load directions, each set repeated on a number of similar specimens. Empirical formulations between the initial shear and compressive strengths of the lock interface are also evaluated.
\end{abstract}

\section{INTRODUCTION}

Under seismic loading, unreinforced masonry walls can fail due to in-plane or out-of-plane loading. In traditional masonry block structures subjected to seismic loading, the joints between the masonry units act as planes of weakness due to their low tensile and shear bond strength. The mechanical behaviour at the joint interfaces has widely been studied within different methods of analysis, e.g. discrete or finite element analysis [1-3] and limit analysis with infinitive [4], or finite isotropic associative [5] and non-associative [6] frictional resistances. In particular, experimental investigation was carried out on 3D dry-stacked units 
to evaluate yield domains in shear, torsion-shear and torsion-shear-bending moment interactions [7] and on the validation of frictional resistances of shear block walls [8].

Increasing interest has recently been devoted to interlocking blocks/interfaces capable to enhance the sliding resistance of masonry joints to external forces. The interlocking blocks are rigid block units which, on their faces, have locks keeping the blocks together and preventing blocks from sliding. Experimental and numerical tests $[9,10]$ investigated the inplane and out-of-plane capacity of masonry walls composed of blocks with corrugated interfaces. Out-of-plane behaviour of osteomorphic blocks and interfaces with cross shaped locks were also experimentally investigated by Dyskin et al. [11] and Ali et al. [12], respectively. Similarly, experimental and numerical investigations were carried out on the different behaviour of wooden joinery connections with different geometric properties [1316]. A digital tool to design structurally feasible masonry structures composed of interlocking blocks is being developed by some of the presenting authors [17-19].

One of the key factors that influence the behaviour and capacity of the conventional mortared block masonry is the bond strength between the mortar and the units. Similarly, the shear strength between the lock and the main body of the interlocking block is of utmost importance for dry masonry with interlocking interfaces. This means that, if the interlocking blocks are composed of cohesive material at their interfaces, the Mohr-Coulomb criterion can be adopted for both systems, for which the bond strength itself depends on the initial shear strength (cohesion) and the coefficient of friction as well as the level of normal stresses.
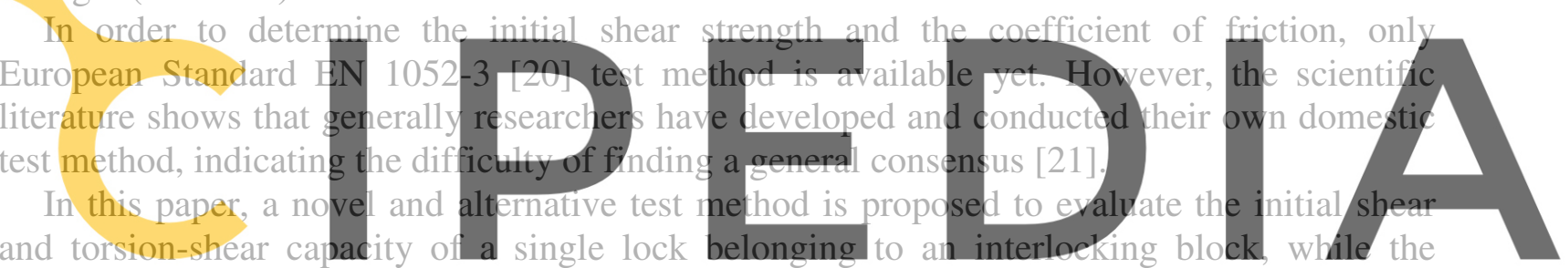

coefficient of friction and shear in presence of normal forces are beyond its scope. The test

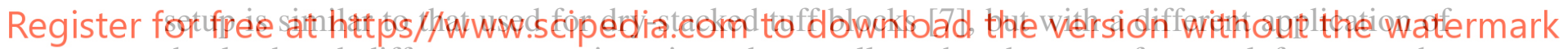
the load and different constraints, in order to allow the absence of normal force on the cohesive interface between the two parts of the block (lock and main body) kept rigid during the tests. The block was specifically designed to reproduce a particular interlocking block shape. The material properties of two selected cement-based mortars were also experimentally evaluated in order to define or confirm empirical relationships between their compressive and initial shear strengths.

\section{EXPERIMENTAL INVESTIGATION}

Representing the simplest interlocking model, a main body with a lock located on its upper face was designed as the specimen for this test. An ad hoc test setup was realized to estimate the pure shear and torsion-shear resistance of the interface at which the lock is connected to the main body, while keeping rigid the lock and the main body of the interlocking block.

A first phase of the research focused on finding the proper shape and dimensions for the block. A number of specimens were made by casting mortars with different mixtures in a mould, provided in the desired shape and dimension by a 3D printer. Then, four different test configurations were set up to simulate shear and torsion-shear failures, herein named sets S1, 
S2, S3 and S4. Besides, calibrating the mechanical properties of the appropriate mortar to be prepared was a crucial issue, both because of the limitations of the involved instrumentation, in particular the maximum capacity of the load cells, and of the necessity of obtaining a clear shear failure mode of the lock interface (cohesive crack). Therefore, trial samples composed of several specimens were casted with different cohesive materials and were tested under pure shear [22]. Finally, two mortars, namely M1 and M2, were chosen and their density, flexural and compressive strengths were experimentally determined.

In sum, eight samples, combining the four sets and the two mortars, were tested. Each of the two samples tested in pure shear, namely S1M1 and S1M2, involved four specimens, while the six samples for torsion-shear tests, comprised three specimens each, in total providing twenty-six experimental results.

The experimental investigation was carried out with standard and non-standard equipment at Laboratory of the Department of Structures for Engineering and Architecture (DiSt) of the University of Napoli Federico II (Italy).

\subsection{Characterization of mortars}

Two different mortars, M1 and M2, were chosen to make the specimens, whose composition and curing time are quoted in Table 1. Pozzolana, so named from the Pozzuoli town, is fine sand or loose blocks that can be easily found, in colours ranging from grey to red $[23,24]$; lime, supplied by Cimmino Calce s.r.l. (Naples), is a calcium-containing inorganic mineral still used in large quantities as building and engineering material. The mixtures were prepared using the consistency. According compacted during the ambient laboratory conditions (relative humidity

Register for free at https//www.scipedia.comp to download the version without the watermark

\begin{tabular}{cccccc}
\hline Mortar & Pozzolana & Sand & Cement & Lime & Curing Time \\
\hline M1 & $50 \%$ & $24 \%$ & $2 \%$ & $24 \%$ & 28 days \\
\hline M2 & $47 \%$ & $38 \%$ & $15 \%$ & - & 28 days \\
\hline
\end{tabular}

These non-standard mixtures were chosen to prepare specimens in the first phase of the experimental program, aimed to obtain: 1) failure load values compatible with the designed setup and within the valid range of the employed instrumentation; 2) failure modes corresponding to instantaneous and clear cutting of the lock from the main block. So, before defining M1 and M2, the traditional pozzolana based mortar [24], obtained with three parts of pozzolana and one of lime, was first employed to cast five specimens, cured in water for 28 days, and tested with pure shear setup. As the limit load $(500 \mathrm{~N})$ of the load cell was reached before any failure on the lock, a new attempt was made by reproducing the same experimental phase in which only the curing time was reduced to 14 days. Applying this change, collapse was achieved in all the specimens, but a relatively concave shape was observed at the failure interface. Then, other mixtures were tested, adding cement with different ratios of components, with sets of five specimens cured in air for different curing times, and finally M1 
and M2 mortars were chosen.

Standard specimens, i.e. rectangular parallelepipeds of 40x40x160mm were also prepared to characterize the mechanical properties of the M1 and M2 mortars, i.e. four for each mortar. Those specimens were measured with a digital calliper and weighted with an electronic weighting machine, to obtain the density of the mortars.

Then, flexural and compressive tests were carried out with standard equipment, following the UNI EN 1015-11 [26]. The mean values of the measured density and strengths are summarized in Table 2.

Table 2: Experimental mechanical properties of the tested mortars

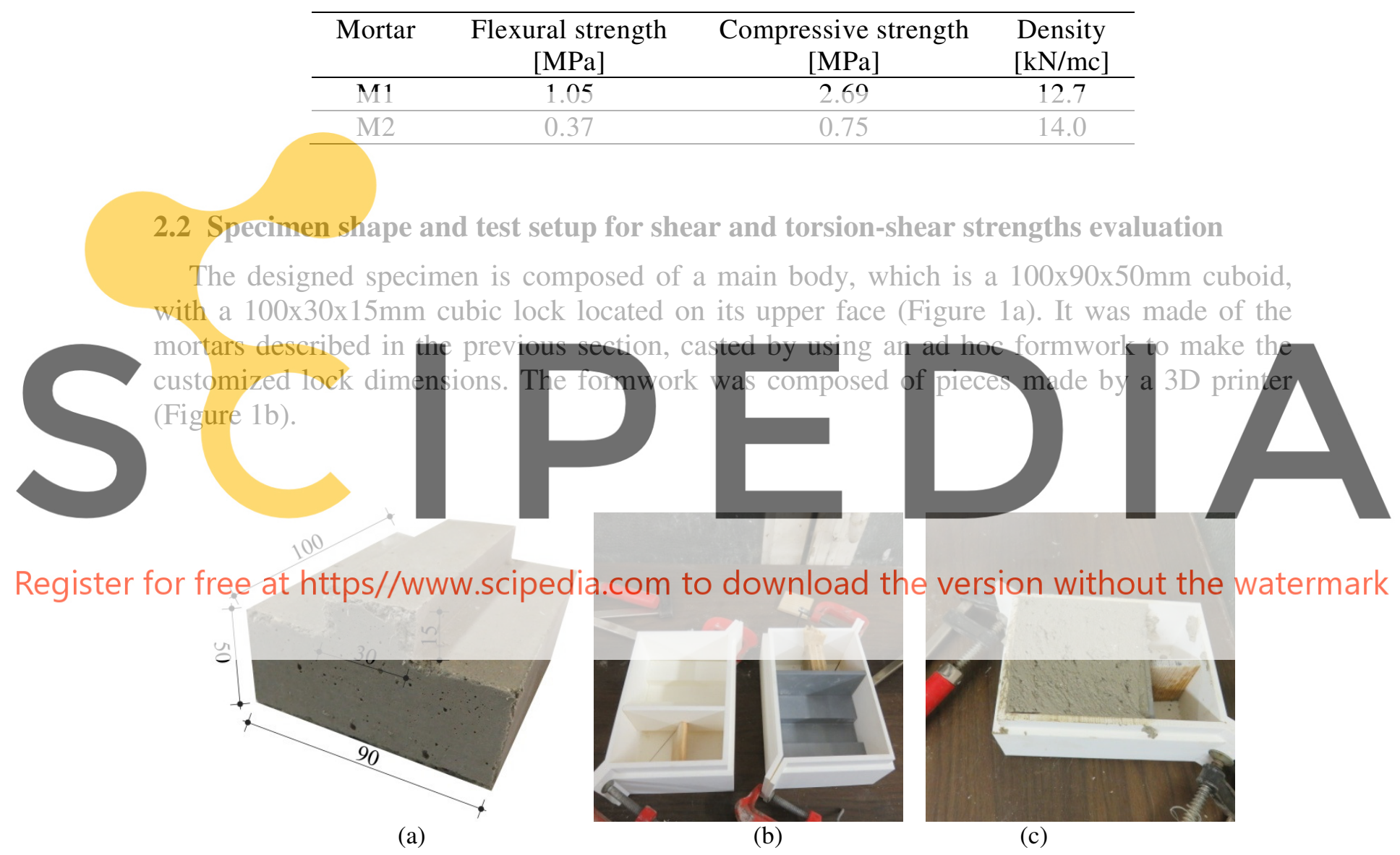

Figure 1: (a) Designed specimen; (b) printed moulds; (c) curing phase

The test setup was specifically designed to pursue pure shear and torsion-shear resistances of the lock interface, overcoming some related issues. In fact, with the aim of minimizing the effect of bending usually experienced during shear tests [21] and of avoiding the precompression force, which are the main challenges of the traditional experimental setup [20], a new setup was developed for the experimental tests.

Actually, a horizontal load was applied directly on the front face of the lock by the static gravity load via a pulley system, while its main body was held fixed, until the collapse of the 
lock occurred. Meanwhile, the test setup, other than measuring pure shear resistance, ought to be efficient in evaluating also torsion-shear failure, by simply changing the load eccentricity. This task was accomplished by changing the position and direction of the designed pulley system.

The test setup is schematically shown in Figure 2a: the horizontal point-load was applied to the side face of the specimen lock by means of an electric hydraulic jack, monotonically increasing until the failure mechanisms. As shown in Figure $2 b$, the block was fixed to a wooden board to avoid sliding and to the upper support to avoid rotation, while the board was fixed to the upper support against sliding as well.

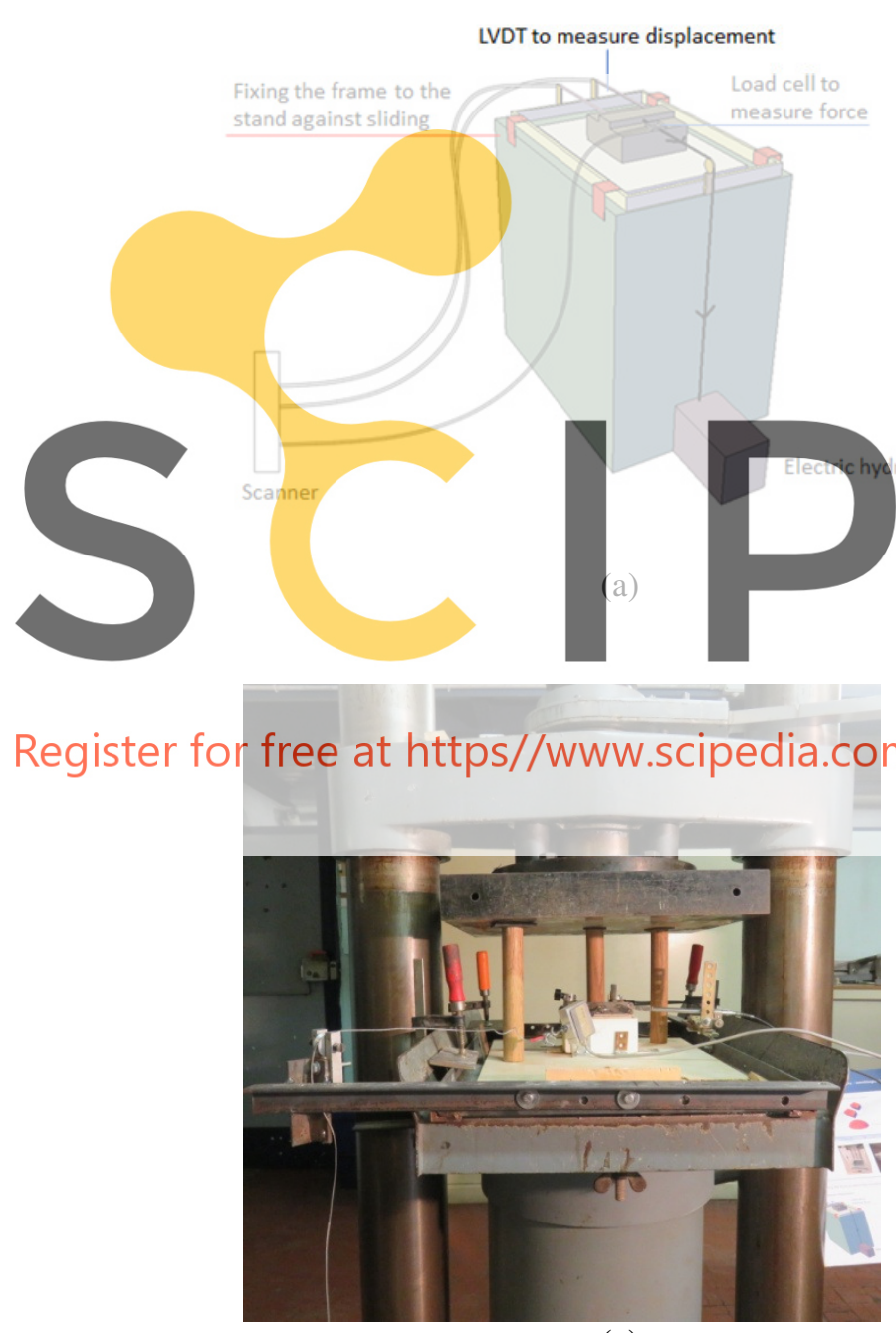

(c)

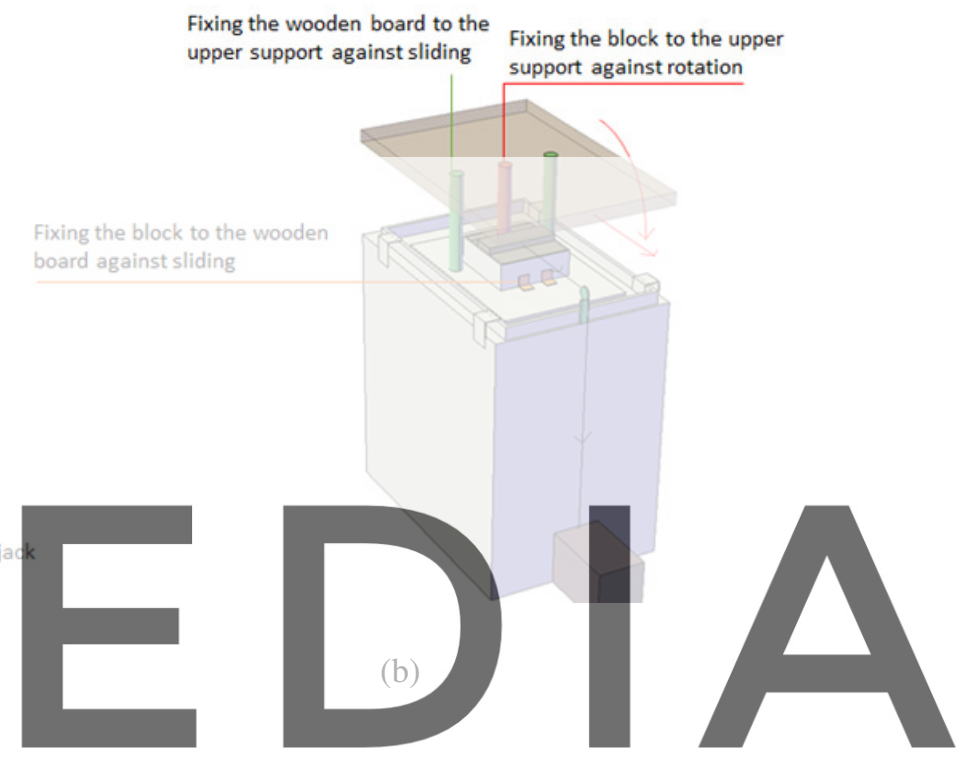

Figure 2: Test setup. (a) Displacement and load measurement; (b) constraints; (c,d) realized torsion-shear setup

The application of an iron cup on the lock allowed both the simulation of this part as a rigid block and the distribution of the applied shear force along the whole lock face (Figure 
3a). On the other hand, the main body of the interlocking block was kept rigid during the tests by using a rigid cup-shaped container, still provided by a 3D printer. The load was applied under displacement control at a constant rate of $3 \mathrm{~mm} / \mathrm{min}$.

Forces were measured using a load cell with a maximum capacity of $500 \mathrm{~N}$ and an acquisition frequency of $10 \mathrm{~Hz}$, while displacements were measured using Linear Variable Displacement Transducers (LVDTs) with a displacement range of $\pm 50 \mathrm{~mm}$. A digital scanner, distributed by Vishay Measurements Group, was employed to acquire transducers data.

With the aim of capturing both pure shear and torsion-shear failures, three LVDTs, supported by a steel frame, were positioned to the lateral and back sides of the lock and numbered as shown in Figure $3 b$.

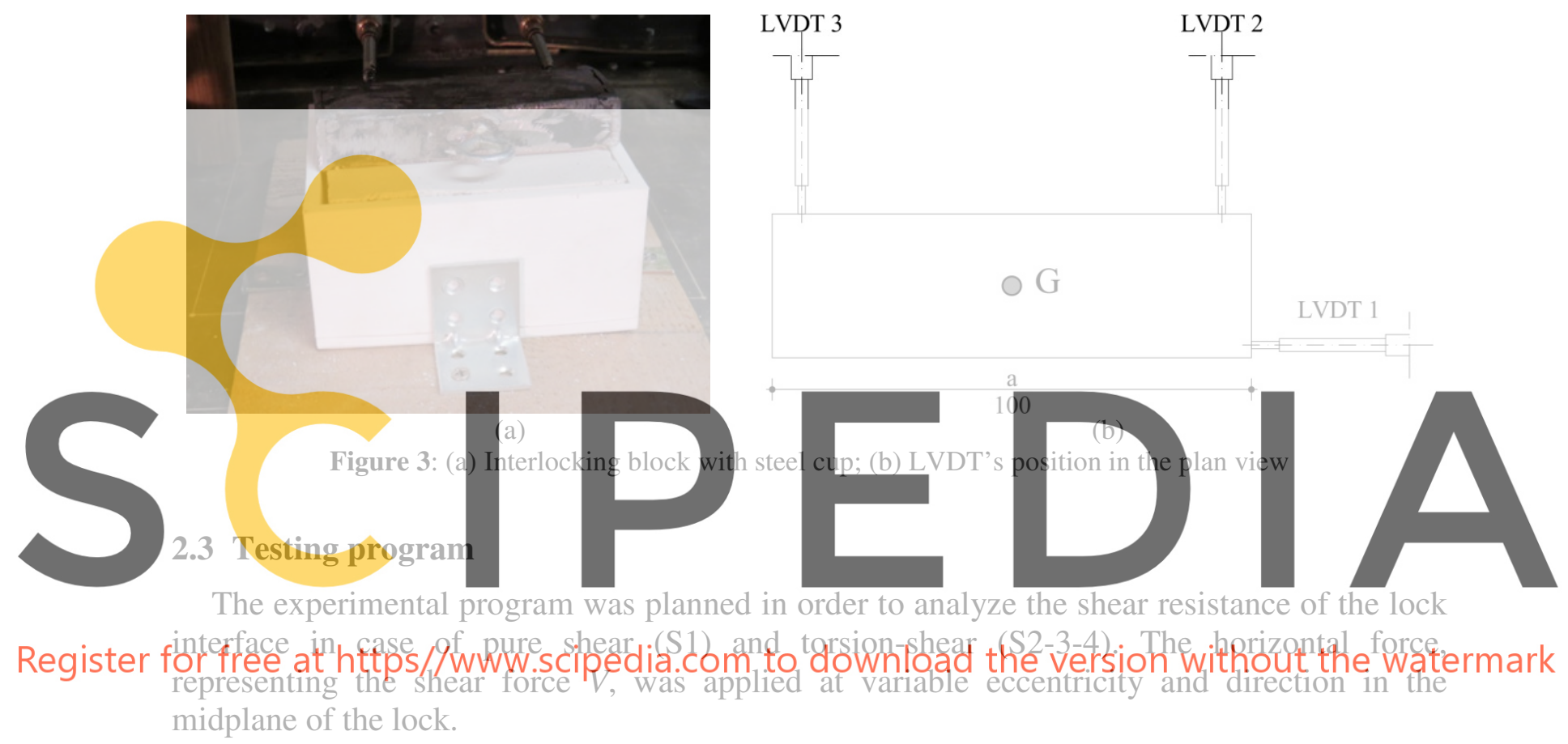

As introduced above, the specimens made of two chosen mortars, M1 and M2, were tested with four setups, resulting in eight samples (Table 3), i.e.:

- $\quad$ S1M1 and S1M2 for pure shear strength evaluation, each comprising four specimens;

- $\quad$ S2M1, S2M2, S3M1, S3M2, S4M1, S4M2 for torsion-shear strength evaluation, each comprising three specimens.

As shown in Table 3, the shear setup (S1) was modified to allow torsion-shear behaviour, in different ways:

- $\quad$ for $\mathrm{S} 2$, the force application point was moved on the lock, with $V$ still orthogonal to the lock front side, applying the eccentricity $e=25 \mathrm{~mm}$ from point $\mathrm{G}$;

- $\quad$ for S3, the force application point was only spaced from the lock with reference to $\mathrm{S} 1$, with $V$ rotated $45^{\circ}$ counterclockwise, applying the eccentricity $e=29 \mathrm{~mm}$;

- $\quad$ for $\mathrm{S} 4$, the force application point was moved on and spaced form the lock, with $V$ rotated $45^{\circ}$ clockwise, applying the eccentricity $e=51 \mathrm{~mm}$. 
Table 3: Experimental set configurations (the distances are in $\mathrm{mm}$ )

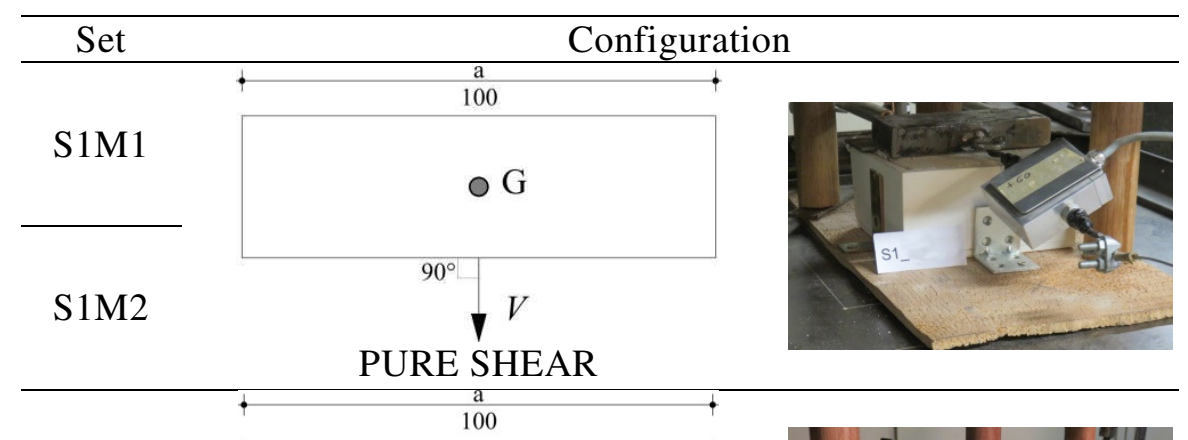

S2M1

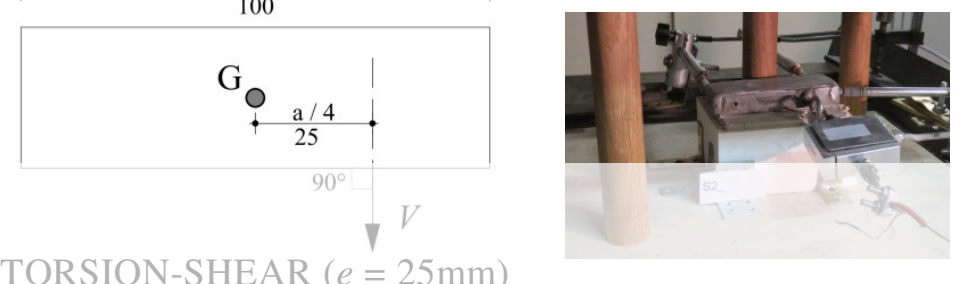

S2M2 TORSION-SHEAR $(e=25 \mathrm{~mm})$
T

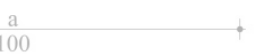

S3M1
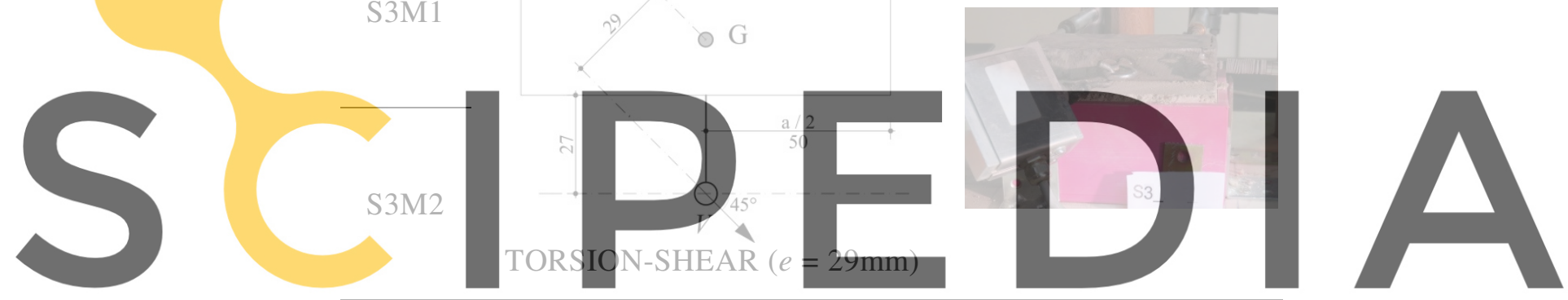

Register for free at https//www.scipedia.com to download the version without the watermark
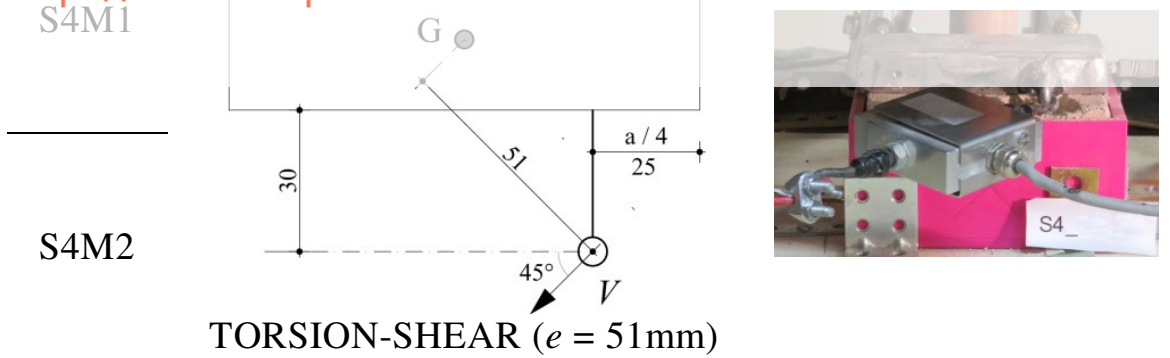

TORSION-SHEAR $(e=51 \mathrm{~mm})$

\section{EXPERIMENTAL RESULTS}

\subsection{Pure shear strength of the two mortars}

In order to determine the pure shear strength (cohesion) of the two mortars, a total of 8 tests were made out for M1 and M2 mortar samples. Using the S1 shear test setup described in the previous section, it was possible to define the force causing the shear collapse of the specimens. The values of this force for the two M1 and M2 mortars are collected in Table 4. 
The coefficients of variation (CV) show a low dispersion of the frequency distributions and therefore a good reliability of the test setup. The average values of the limiting forces related to pure shear failure are equal to $431 \mathrm{~N}$ and $240 \mathrm{~N}$ for the M1 and M2 mortar, respectively. The greater shear resistance of the M1 mortar compared to M2 is in good agreement with similar trends for the compressive and flexural strength results shown in Table 2.

Table 4: Pure shear resistance of the two M1 and M2 mortars for S1 tests

\begin{tabular}{ccccccc}
\hline \multirow{2}{*}{ Mortar } & \multicolumn{4}{c}{ Shear resistance $V[\mathrm{~N}]$} & \multirow{2}{*}{ CV [\%] } & $\begin{array}{c}\text { Average } V \\
{[}\end{array}$ \\
\cline { 2 - 5 } & $\mathrm{T} 1$ & $\mathrm{~T} 2$ & $\mathrm{~N} 3$ & $\mathrm{~T} 4$ & \\
\hline M1 & 399 & 472 & 408 & 445 & 6.8 & 431 \\
\hline M2 & 250 & 242 & 226 & 243 & 3.7 & 240 \\
\hline
\end{tabular}

For this setup (pure shear), two LVDTs were used to verify the effective displacements of the lock in the absence of torsion. Figure 4 shows the load-displacement curves referred to some of the four tests performed on each of the M1 and M2 mortars, i.e. T2 Test in Figure 4a, and T1 and T3 Tests in Figure 4b. From these figures it is first evident the quasi-brittle behaviour of the material for both mortars. It is then worth emphasizing that the displacements of the two LVDTs, registered as channels Ch.2 and Ch.3 in the figure, substantially tend to overlap for each test. This result confirms once again the reliability of the setup realized ad hoc in the laboratory; in fact, the specimens collapsed in pure shear as there

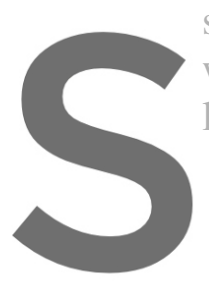
was no torsion effect. limiting forces collected for the Register for free at https//www.scipedia.com to co
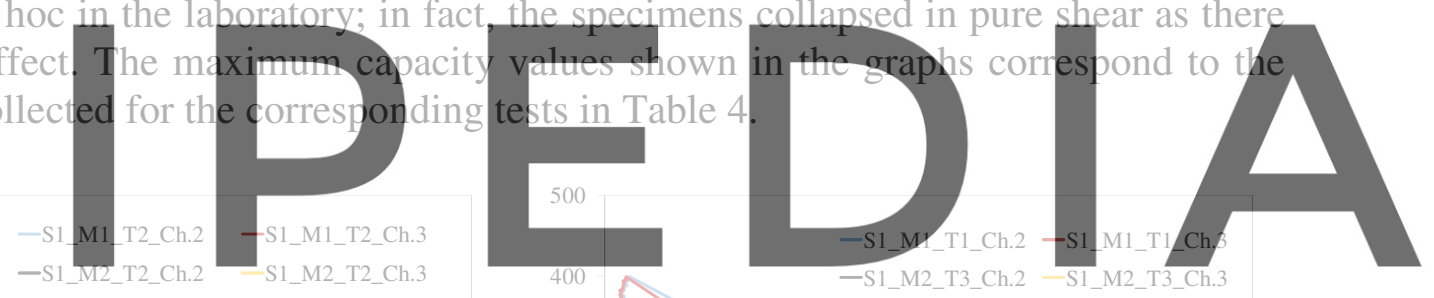

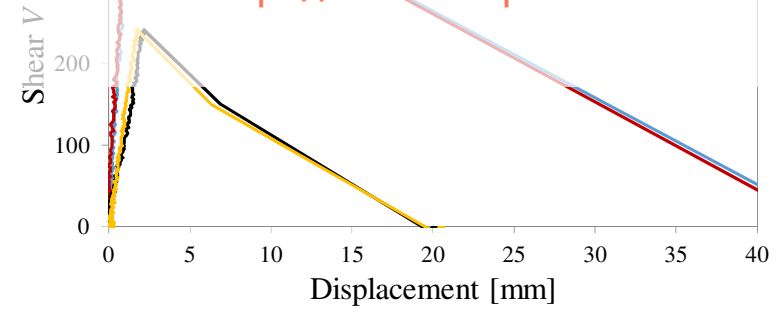

(a)

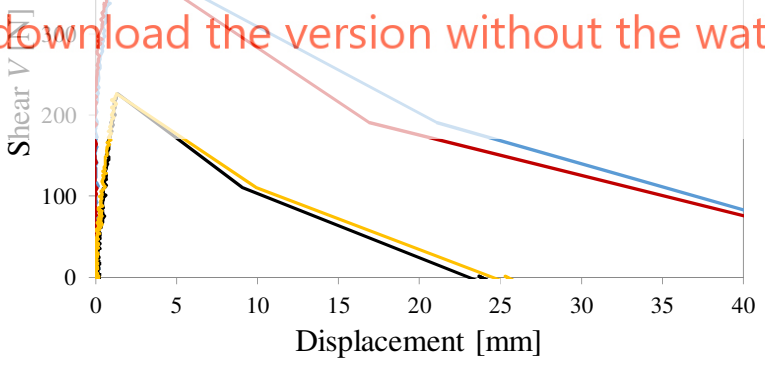

(b)

Figure 4: Load-displacement curves for S1 tests: (a) M1_T2 - M2_T2 and (b) M1_T1- M2_T3

Assuming a uniform distribution of the limiting shear force along the interface $(100 \times 30 \mathrm{~mm})$ between the lock and the main body of the specimens, the mean shear strength $f_{v}$ can easily be derived for each tested mortar. The relationship between the experimental shear and compressive strengths are reported in Table 5, taking into account the values in Table 2. These results seem to confirm the reliability of the empirical formulation developed by Ali et al. [27], which fits experimental results on standard triplets of masonry and mortar and provides a relation between the mean bond shear strength in absence of normal stresses 
(cohesion), and the compressive strength of mortar. The formulation is:

$$
f_{v}=0.06 f_{m}^{0.8389}
$$

where $f_{m}$ is the compressive strength of mortar.

In fact, although this formulation was tested for mortars with compressive strengths greater than those of M1 and M2, the pure shear strengths obtained with this formulation for M1 and M2 are very close to the experimental results, as reported in Table 5.

Table 5: Relation between pure shear and compressive strengths of the two M1 and M2 mortars for S1 test

\begin{tabular}{ccccc}
\hline Mortar & $\begin{array}{c}\text { Shear strength } \\
{[\mathrm{MPa}]}\end{array}$ & $\begin{array}{c}\text { Compressive } \\
\text { strength } \\
{[\mathrm{MPa}]}\end{array}$ & $\begin{array}{c}\text { Shear } \\
\text { strength/compressive } \\
\text { strength ratio }\end{array}$ & $\begin{array}{c}\text { Shear strength according } \\
\text { to Eq. (1) [27] } \\
{[\mathrm{MPa}]}\end{array}$ \\
\hline $\mathrm{M} 1$ & 0.15 & 2.69 & $5.6 \%$ & 0.14 \\
\hline $\mathrm{M} 2$ & 0.08 & 0.75 & $10.7 \%$ & 0.05 \\
\hline
\end{tabular}

\subsection{Torsion-shear strength of the two mortars}

The S2-3-4 setups were developed to analyze the torsion-shear resistance of the lock. These setups differ from each other in the eccentricity of the applied force. To determine the torsion-shear strength of the two mortars, a total of 18 specimens, three per each set and mortar, were made out on the M1 and 12 mortar samples, as reported in Table 6. The first
interesting remark is that the values of the forces $V$ related to torsion-shear failure of edch
mortar decrease with increasing eccentricity, as expected. The small coefficients of variation
$\mathrm{CV}$, except one, still show quite a good reliability of the setup adopted.

Table 6: Torsion-shear resistance of the two M1 and M2 mortars for S2-3-4 tests

Register for free at https//www.scipedia.com to download the version without the watermark

\begin{tabular}{|c|c|c|c|c|c|c|c|}
\hline \multirow{2}{*}{ Set } & \multirow{2}{*}{$\begin{array}{l}\text { ecc. } \\
{[\mathrm{mm}]}\end{array}$} & \multirow{2}{*}{ Mortar } & \multicolumn{3}{|c|}{ Shear force $V[\mathrm{~N}]$} & \multirow{2}{*}{ CV [\%] } & \multirow{2}{*}{$\begin{array}{c}\text { Average } V \\
{[N]}\end{array}$} \\
\hline & & & T1 & $\mathrm{T} 2$ & T3 & & \\
\hline \multirow{2}{*}{2} & \multirow{2}{*}{25} & M1 & 314 & 300 & 330 & 3.9 & 315 \\
\hline & & M2 & 213 & 203 & 181 & 6.7 & 199 \\
\hline \multirow{2}{*}{3} & \multirow{2}{*}{29} & M1 & 243 & 260 & 276 & 5.2 & 260 \\
\hline & & M2 & 181 & 193 & 192 & 2.9 & 189 \\
\hline \multirow{2}{*}{4} & \multirow{2}{*}{51} & M1 & 79 & 177 & 195 & 33.9 & 150 \\
\hline & & M2 & 118 & 133 & 106 & 9.3 & 119 \\
\hline
\end{tabular}

On the other hand, through the load-displacement curves in Figure 5, it is possible to confirm the quasi-brittle behaviour of the involved materials and to analyze the rotation of the lock until collapse and its consistency with the eccentric load applied. Unlike the curves for pure shear in Figure 4, where the displacements of LVDT 2 and 3 tend to coincide, for the torsion-shear condition the displacements are very different from each other. Specifically, the displacement of the LVDT Ch.3 is generally between $\pm 0.5 \mathrm{~mm}$, while the displacements recorded by the LVDT Ch.2 are even six times higher. Using three LVDTs allows to record three final displacements at the moment of the lock failure and therefore to build the final 
deformation. Further investigation will be carried out to define the pure torsion strength as well, so that analytical yield domains in torsion-shear interaction can be experimentally validated, similarly to what developed by Casapulla and Portioli [7] for dry-stacked tuff blocks.
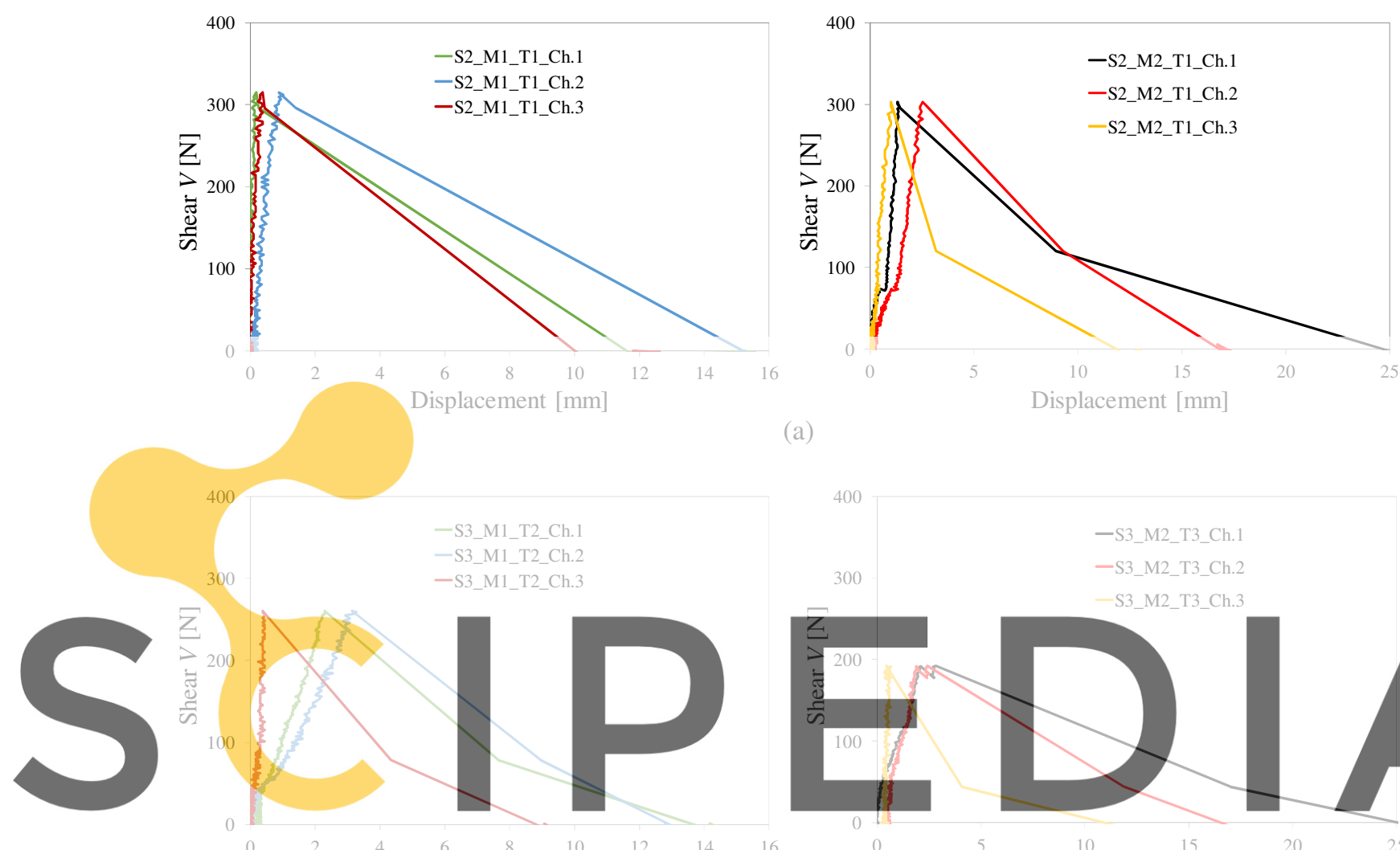

(a)

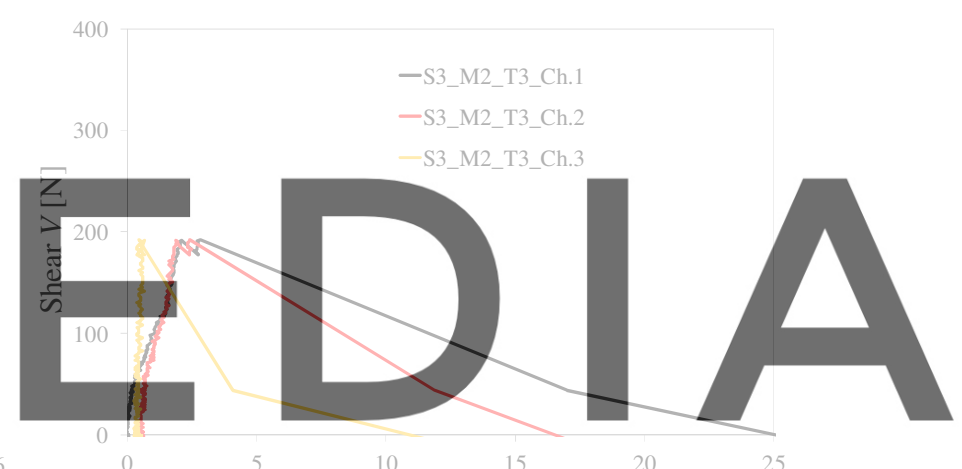

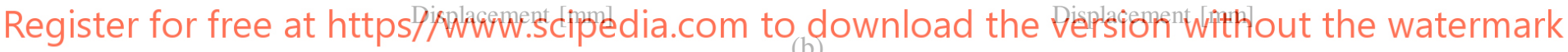

Figure 5: Load-displacement curves for S2 and S3 tests and: (a) M1 and (b) M2 mortars

\section{CONCLUSIONS}

Interlocking blocks/interfaces are capable to enhance the shear resistance of masonry joints to external forces, including seismic loading. If the interlocking blocks are composed of cohesive material at their interfaces, the mechanical behaviour is governed by the MohrCoulomb criterion for which the bond strength at these interfaces depends on initial shear strength (cohesion) and the coefficient of friction as well as the level of normal stresses.

This paper describes the experimental investigation carried out on the simplest interlocking block, composed of a main body with a prismatic lock located on its upper face and subjected to lateral loading in absence of normal force. An ad hoc test setup was realized to estimate the initial shear and torsion-shear strengths at the lock interface, with results reported in terms of load-displacement curves. Two cement-based mortars were used for specimens, casted using moulds provided by a 3D printer.

The first interesting experimental outcome is that the proposed domestic test method is reliable enough compared to others existing in the literature to assess the shear and torsion- 
shear strength of cement-based mortars with low compressive and flexural strengths. In fact, using three LVDTs in key positions, pure translation of the lock was registered in the case of pure shear failure and twisting deformation was possible to be captured in the case of torsionshear condition. Another interesting remark is that the relation between the experimental initial shear and compressive strengths of the lock interface is very close to the empirical formulation developed by Ali et al. [27], which fits experimental results on standard triplets of masonry and mortar. This result can be very useful when analysing limit conditions of assemblages of masonry interlocking blocks composed of material of known compressive strength. Further work is under development to evaluate the torsion-shear yield domain for the single lock interface and to extend the test method to interlocking blocks composed by a number of locks.

Acknowledgements.

This project has received funding from the European Union's Horizon 2020 research and innovation programme, under the Marie Skłodowska-Curie Grant Agreement No. 791235, and from the Italian Civil Protection, through the RELUIS Project WP4: MAppe di Rischio e Scenari di danno sismico (MARS) (2020). The authors wish to express their gratitude to Mr. Domenico Imperatrice from the Laboratory of DiSt in Napoli, for his helpful assistance and support in the execution of the experimental investigations.

\section{REFERENCES}

[1] Lourenço, P.B., Rots, J.G. and Blaauwendraad, J. Two approaches for the analysis of masonry structures: micro and macro-modeling. Heron (1995) 40(4):1-28.

[2] Li, T. and Atamturktur, S. Fidelity and robustness of detailed micromodeling, simplified micromodeling, and macromodeling techniques for a masonry dome. J. Perform. Constr. Fac. (2013) 28(3):480-490.

[3] Cannizzaro, F., Pantò, B., Caddemi, S. and Caliò, I. A Discrete Macro-Element Method (DMEM) for the nonlinear structural assessment of masonry arches. Eng. Struct. (2018) 168:243-256.

[4] Heyman, J. The stone skeleton: structural engineering of masonry architecture. Cambridge University Press (1995).

[5] Livesley, R.K. A computational model for the limit analysis of three-dimensional masonry structures. Meccanica (1992) 27(3):161-172.

[6] Casapulla, C., Giresini, L., Argiento, L.U. and Maione, A. Nonlinear static and dynamic analysis of rocking masonry corners using rigid macro-block modelling. Int. J. Struct. Stab. Dy. (2019) 19(11): art. no. 1950137, 1-32.

[7] Casapulla, C. and Portioli, F. Experimental tests on the limit states of dry-jointed tuff blocks. Mater. Struct. (2016) 49(3):751-767.

[8] Casapulla, C., Argiento, L.U. and Ceraldi, C. Experimental validation of in-plane frictional resistances in dry block masonry walls. In: M. Papadrakakis and M. Fragiadakis (Eds.): Computational Methods in Structural Dynamics and Earthquake Engineering (COMPDYN 2017), ECCOMAS Bookseries 1 (2017), pp. 2607-2618.

[9] Liu, H., Liu, P., Lin, K. and Zhao, S. Cyclic behavior of mortarless brick joints with different interlocking shapes. Materials (2016) 9(3): art. no. 166.

[10]Hossain, M.A., Totoev, Y. and Masia, M.J. Friction on mortar-less joints in semi 
interlocking masonry. In: C. Modena et al. (Eds.): Brick and Block Masonry, CRC Press (2016), pp. 1635-1643.

[11]Dyskin, A.V., Estrin, Y. and Pasternak, E. Topological Interlocking Materials, In: Y. Estrin et al. (Eds.): Architectured Materials in Nature and Engineering, Berlin, Springer (2019), pp. 23-49.

[12] Ali, M., Gultom, R.J. and Chouw, N. Capacity of innovative interlocking blocks under monotonic loading. Constr. Build. Mater. (2012) 37:812-821.

[13]Ceraldi, C., D'Ambra, C., Lippiello, M. and Prota, A. Restoring of timber structures: connections with timber pegs. Eur. J. Wood Wood Prod. (2017) 75(6):957-971.

[14]Ceraldi, C., Lippiello, M., D'ambra, C. and Prota, A. The influence of dowel-bearing strength in designing timber pegged timber joints. Int. J. of Archit. Herit. (2018) 12(3):362-375.

[15]Fang, D. and Mueller, C.T. Joinery connections in timber frames: analytical and experimental explorations of structural behavior. In: Annual IASS Symposium 2018, IASS (2018), pp. 1-8.

[16] Sassu, M., De Falco, A., Giresini, L. and Puppio, M. Structural solutions for low-cost bamboo frames: Experimental tests and constructive assessments. Materials (2016) 9(5): art. no. 346.

[17] Casapulla, C., Mousavian, E. and Zarghani, M. A digital tool to design structurally feasible semi-circular masonry arches composed of interlocking blocks. Comput. Struct. (2019) 221:111-126.

[18] Mousavian, E. and Casapulla, C. The role of different sliding resistances in limit analysis of hemispherical masonry domes. Frattura ed Integrità Strutturale (2020) 51:336-355.

[19] Mousavian, E. and Casapulla, C. Structurally informed design of interlocking block assemblages using limit analysis. J. Comput Des. Eng., in press.

[20] UNI EN 1052-3 (2007). Methods of test for masonry - Part 3: Determination of initial shear strength.

[21] Montazerolghaem, M. and Jäger, W. A Comparative Numerical Evaluation of Masonry Initial Shear Test Methods and Modifications Proposed for EN 1052-3. In: 9th International Masonry Conference (9IMC), Guimarães, Portugal, 2014, pp. 1-10.

[22] Sassu, M., Giresini, L., Bonannini, E. and Puppio, M.L. On the use of vibro-compressed units with bio-natural aggregate. Buildings (2016) 6(3): art. no. 40.

[23] Lippiello, M., Ceraldi, C., D'Ambra, C. and Lignola, G.P. Mechanical characterization of ancient pozzolanic mortars with additions of brick and tuff dust: a comparative investigation. In: K. Van Balen and E. Verstrynge (Eds.): Structural Analysis of Historical Constructions, Taylor \& Francis Group (2016), pp. 558-564.

[24]Lippiello, M. Pozzolanic cementum of the ancient constructions in Campi Flegrei area. Int. J. of Archit. Herit. (2011) 5(1):84-100.

[25] UNI EN 1015-2 (2007). Methods of Test for Mortar for Masonry - Part 2: Bulk sampling of mortars and preparation of test mortars.

[26] UNI EN 1015-11 (2007). Methods of Test for Mortar for Masonry - Part 11: Determination of flexural and compressive strength of hardened mortar.

[27] Ali, N., Ashraf, M., Alam, H. and Ahmed Khan, F. Effect of precompression and mortar ratios on the in-plane shear strength of unreinforced brick masonry. Int. J. Advanced Structures and Geotechnical Engineering (2016) 5(3):78-82. 